\title{
BMJ Open Scoping review of systematic reviews of complementary medicine for musculoskeletal and mental health conditions
}

\author{
Ava Lorenc, ${ }^{1}$ Gene Feder, ${ }^{1}$ Hugh MacPherson, ${ }^{2}$ Paul Little, ${ }^{3}$ Stewart W Mercer, ${ }^{4}$ \\ Deborah Sharp ${ }^{1}$
}

To cite: Lorenc A, Feder G, MacPherson $\mathrm{H}$, et al. Scoping review of systematic reviews of complementary medicine for musculoskeletal and mental health conditions. BMJ Open 2018;8:e020222. doi:10.1136/ bmjopen-2017-020222

- Prepublication history and additional material for this paper are available online. To view please visit the journal (http:// dx.doi.org/10.1136/bmjopen2017-020222).

Received 30 0ctober 2017

Revised 14 June 2018 Accepted 1 August 2018

Check for updates

(C) Author(s) (or their employer(s)) 2018. Re-use permitted under CC BY-NC. No commercial re-use. See rights and permissions. Published by BMJ.

${ }^{1}$ Population Health Sciences, Bristol Medical School, Bristol, UK

2Department of Health Sciences, University of York, York, UK ${ }^{3}$ Primary Care and Population Science Unit, University of Southampton, Southampton, UK ${ }^{4}$ General Practice and Primary Care, Institute of Health and Wellbeing, University of Glasgow, Glasgow, UK

Correspondence to

Dr Ava Lorenc;

ava.Iorenc@bristol.ac.uk

\section{ABSTRACT}

Objective To identify potentially effective complementary approaches for musculoskeletal (MSK)-mental health (MH) comorbidity, by synthesising evidence on effectiveness, cost-effectiveness and safety from systematic reviews (SRs).

Design Scoping review of SRs.

Methods We searched literature databases, registries and reference lists, and contacted key authors and professional organisations to identify SRs of randomised controlled trials for complementary medicine for MSK or MH. Inclusion criteria were: published after 2004, studying adults, in English and scoring $>50 \%$ on Assessing the Methodological Quality of Systematic Reviews (AMSTAR); quality appraisal checklist). SRs were synthesised to identify research priorities, based on moderate/good quality evidence, sample size and indication of costeffectiveness and safety.

Results We included 84 MSK SRs and 27 MH SRs. Only one focused on MSK-MH comorbidity. Meditative approaches and yoga may improve $\mathrm{MH}$ outcomes in MSK populations. Yoga and tai chi had moderate/good evidence for MSK and MH conditions. SRs reported moderate/good quality evidence (any comparator) in a moderate/large population for: low back pain (LBP) (yoga, acupuncture, spinal manipulation/mobilisation, osteopathy), osteoarthritis (OA) (acupuncture, tai chi), neck pain (acupuncture, manipulation/manual therapy), myofascial trigger point pain (acupuncture), depression (mindfulness-based stress reduction (MBSR), meditation, tai chi, relaxation), anxiety (meditation/MBSR, moving meditation, yoga), sleep disorders (meditative/mind-body movement) and stress/distress (mindfulness). The majority of these complementary approaches had some evidence of safety - only three had evidence of harm. There was some evidence of cost-effectiveness for spinal manipulation/ mobilisation and acupuncture for LBP, and manual therapy/ manipulation for neck pain, but few SRs reviewed costeffectiveness and many found no data.

Conclusions Only one SR studied MSK-MH comorbidity. Research priorities for complementary medicine for both MSK and MH (LBP, OA, depression, anxiety and sleep problems) are yoga, mindfulness and tai chi. Despite the large number of SRs and the prevalence of comorbidity, more high-quality, large randomised controlled trials in comorbid populations are needed.
Strengths and limitations of this study

- A comprehensive scoping review covering a wide range of individual musculoskeletal and mental health conditions, in the notable dearth of systematic reviews (SRs)/randomised controlled trials in comorbid populations.

- This review used systematic searching and screening techniques.

- Results are limited by our pragmatic choice to only include high-quality SRs (high scoring on AMSTAR checklist (Assessing the Methodological Quality of Systematic Reviews)) and definition of complementary medicine as including a practitioner in its delivery.

- Date and language limitations may have excluded some topics.

\section{INTRODUCTION}

Musculoskeletal (MSK) and mental health (MH) disorders are two conditions resulting in some of the highest burden in terms of disability, accounting for $30.5 \%$ and $21.1 \%$ of years lived with disability, respectively. ${ }^{1}$ Both affect one in four UK adults at some point in their life. ${ }^{2-4}$ MSK disorders lead to very high healthcare expenditure and loss of work, ${ }^{5}$ in the UK accounting for 7.5 million working days lost annually ${ }^{6}$ and $60 \%$ of occupational sick leave. ${ }^{2}$ In England, it has been estimated that $\mathrm{MH}$ costs $£ 105$ billion, and treatment costs are expected to rise substantially. ${ }^{7}$

Low back pain (LBP) is one of the most common health conditions, ${ }^{8-10}$ with a mean global general population prevalence (regardless of prevalence period) of $31 \%^{10}$ and a UK prevalent population of 17.3 million, with 3.1 million adults suffering during an entire year, ${ }^{11}$ costing the National Health Service (NHS) over $£ 500$ million/year. ${ }^{12}$ In the UK, 8.75 million people sought primary care treatment for osteoarthritis (OA) (over a 7-year 
consultation period $)^{13}$ which is estimated to have resulted in $£ 14.8$ billion indirect costs. ${ }^{14}$

The most common MH conditions are depression and anxiety. ${ }^{34}$ In England, 19\% of the general adult population reported ever being diagnosed with depression and $6 \%$ ever being diagnosed with generalised anxiety disorder. ${ }^{15}$ Insomnia is another common MH problem, affecting $6.4 \%$ of the UK general population. ${ }^{16}$

There is an increasing recognition of the importance of multimorbidity, that is, the coexistence of two or more physical and/or mental long-term conditions in an individual, which is becoming the norm in the UK. ${ }^{17-19}$ In a cross-sectional study in Scotland, $8.3 \%$ of primary care patients (36\% of those with multimorbidity) had both a physical and a MH disorder ${ }^{20}$ and around $50 \%$ of patients with depression had pain symptoms. ${ }^{21}$ Long-term MSK disorders are closely associated with multimorbidity. ${ }^{22}$

Complementary medicine is 'a diverse group of health-related therapies and disciplines which are not considered to be a part of mainstream medical care', including osteopathy, chiropractic, acupuncture, herbal medicine and homeopathy. ${ }^{23}$ Estimates of 12-month prevalence of use of any complementary medicine are $0.3 \%-$ $86 \%$ in Europe ${ }^{24}$ and 26\% in England. ${ }^{25}$

Many MSK and MH conditions, and comorbid MSK and $\mathrm{MH}$, have limited conventional treatment options, 'effectiveness gaps', which are potential key areas for complementary medicine. ${ }^{26}{ }^{27}$ Both $\mathrm{MH}^{28-30}$ and $\mathrm{MSK}^{2431}$ are common reasons for patients to use complementary medicine. We used scoping methodology to identify priority areas where complementary medicine may be useful. ${ }^{32}$ The overall aim of scoping studies is 'to map rapidly the key concepts underpinning a research area and the main sources and types of evidence available' in a formal, systematic and transparent way (which is often lacking in research priority setting exercises) ${ }^{33}$ Scoping study methodology was used to identify gaps in the research base and priorities for future research. Scoping work is an essential step in the development of a strategy for the integration of complementary medicine with conventional care. ${ }^{27}$ Preliminary searches showed that evidence for comorbid populations was very limited, so we chose to include independent evidence on MSK and $\mathrm{MH}$ conditions. This review was part of a wider scoping study, which obtained a breadth of perspectives-the results of this review were combined with findings from consultation with conventional and complementary medicine practitioners, a public survey and case studies of NHS provision of complementary medicine, to inform the final choice of conditions and complementary medicine approaches for a randomised controlled trial (RCT).

\section{METHODS}

The scoping study followed Arksey and O'Malley's ${ }^{32}$ framework plus the refinements suggested by Levac et $a l,{ }^{34}$ Daudt $e t a l^{35}$ and Colquhoun et al. ${ }^{36}$ Scoping reviews are broader and more exploratory than systematic reviews
(SRs). They review a large number of papers to map the evidence-focussing on breadth rather than detail; have few preconceived ideas regarding focus (particularly types of MSK/MH in this context); do not necessarily assess individual study quality; and use a narrative approach to analysis, rather than synthesising or aggregating quantitative data. ${ }^{32}$ The reader is advised to refer to the original SRs we have included for more detailed content.

\section{Aims}

This study aimed to identify which practitioner-based complementary approaches have evidence for both MSK disorders and MH conditions in order to identify research priorities in terms of treatment choice and specific patient groups/conditions for a future pragmatic trial of comorbid MSK and MH in UK primary care. The specific aims were to:

- Collate the evidence on effectiveness, cost-effectiveness and safety from recent SRs of trials of complementary medicine for MSK and MH conditions.

- Identify areas where there is high-quality evidence of effectiveness but sufficient uncertainty to justify a trial.

- Identify areas where there is also some evidence of cost-effectiveness and safety.

\section{Searches}

As this was a scoping review, we used a wide range of methods to identify SRs (published, unpublished, in progress). Literature databases were searched (see below for details of searches): AMED, Medline, EMBASE, CINAHL, PsycINFO; Index to theses; Cochrane library; Epistemonikos; SIGLE. Three trial registries were searched (UKCRN, Health service research projects in progress, Prospero). Reference lists of 'overviews of SRs' and reports (from professional/patient organisations) were searched. We emailed key authors in the field. We also asked the project team, steering group and public and patient involvement (PPI) group, and used websites/social media (university websites, Research Gate and Twitter) to access the wider research community. We asked patient and professional organisations to ask their members for any information (by email, newsletters or social media). These included: disease-specific organisations, for example, Arthritis Research UK, Back Care and MIND; complementary medicine organisations, for example, Research Council for Complementary Medicine and Complementary and Natural Healthcare Council; primary care organisations, for example, UK Royal College of General Practitioners. We presented at one conference and distributed a flyer at another. We contacted the authors of eligible conference abstracts and protocols to ascertain if the SR was available, that is, submitted or in press.

For complementary medicine, we used MeSH terms or subject headings, plus additional terms for complementary medicine which were not indexed. To ensure relevance to UK primary care, we only included complementary approaches which involve practitioner-led 
treatment. We therefore excluded herbal medicine, as the majority of studies do not involve a practitioner. We included manipulation, manual therapy and mobilisation as techniques commonly practised by some complementary medicine practitioners (as well as conventional practitioners). For MSK conditions, we used 'musculoskeletal diseases/disorders' as index terms, adding in any which were missing. For MH, we searched for common, minor MH disorders and symptoms, excluding long-term/severe mental illnesses. Thus, words in titles/abstracts were searched for (rather than subject headings), with reviews needing to include patients with MH symptoms/diagnoses rather than just measuring MH outcomes. See online supplementary appendix 1 for a full list of included and excluded non MSK or MH conditions.

Database searches were conducted in June 2015 and updated in February 2016, in collaboration with a librarian. We used filters for SRs. We excluded reviews published pre-2005, in order to make the final number of papers manageable with minimal impact on our results (given that the majority of SRs were published in 2010 and after (122/158 SRs)). We only included English language reviews. Databases were searched for two topics: complementary medicine+musculoskeletal disorders and complementary medicine+mental health. See online supplementary appendix 1 for details and supplementary appendix 2 for an example search.

We used the inclusion/exclusion criteria (see online supplementary appendix 1) to screen the results from each search. This was a multistage process involving the whole project team. AL screened the titles of all search results, and DS checked the results, with any disagreements discussed and inclusion criteria amended accordingly. AL then screened the abstracts, which were also independently screened by another author. Results were compared, any disagreements discussed and the criteria again amended accordingly. Any remaining disagreements were discussed and resolved with a third author. AL then screened the full text of the agreed papers.

\section{Data extraction}

AL extracted the following data from each SR: author, year, location, complementary medicine/s, health condition/s, for MSK reviews whether MH was included and for MH reviews whether findings applied to MSK populations, methodological features (sources searched, inclusion/exclusion criteria, quality assessment), results and conclusions (effectiveness, safety, cost-effectiveness). Where possible, these data were copied and pasted directly, to avoid any misinterpretation.

\section{Quality appraisal of SRs}

Although not essential, ${ }^{32}$ quality assessment is recommended in scoping reviews. ${ }^{37}$ We used a limited quality appraisal of SRs to help inform prioritisation, using AMSTAR (Assessing the Methodological Quality of Systematic Reviews), a validated checklist. ${ }^{38}$ Due to time constraints and the number of SRs to be appraised, a simple procedure was followed, using the 'search' function in the text of SRs to find particular terms. The emphasis was on obtaining relative scores, allowing ranking of the included reviews, rather than an absolute score of quality. For each of the 11 items on the AMSTAR checklist, a score of 0 was given if they did not meet the criteria or if information was unavailable, a score of 1 if the criteria was met. The scores were summed to give a score for each SR out of a total of 11 .

Any reviews which scored 5 or less (half of the possible total) on AMSTAR were not considered in the evidence synthesis.

\section{Evidence synthesis}

In line with Arksey and O'Malley's ${ }^{32}$ framework for conducting scoping reviews, we used a 'descriptiveanalytical' method, based on the narrative tradition, applying a common analytical framework to the reviews. Evidence synthesis was performed by AL and all authors met regularly to discuss the process and emerging results.

Reviews were placed into a matrix of health condition/ symptom versus complementary medicine, for example, LBP and acupuncture (see tables 1 and 2).

Where there was more than one SR in an area, one (occasionally more than one-where they studied different interventions, eg, types of manipulation) was prioritised, based on recency, breadth, quality (AMSTAR score) and level of analysis (eg, meta-analysis).

There were three steps to the evidence synthesis: step 1: extraction and narrative synthesis of data from prioritised SRs: step 2: ranking of areas (condition vs complementary medicine) using an Excel framework (see below for ranking criteria); and step 3: computation of sample size.

\section{Step 1 data extraction}

For each area (condition vs complementary medicine) in the matrix, data were synthesised for:

- Effectiveness: the conclusions on effectiveness were extracted from the prioritised SR/s, including information on comparator and outcomes.

- Quality of studies: in line with guidance on scoping reviews, ${ }^{32}$ we did not assess the quality of the individual RCTs in each SR, but synthesised the SR authors' conclusions about quality, from the prioritised review/s. We had three categories of quality: poor, moderate or good. Moderate included SRs reporting mixed results.

- Safety: any information on safety was synthesised across all the included SRs.

- Cost-effectiveness: any information on cost-effectiveness was synthesised across all the included SRs.

\section{Step 2 ranking}

Using the information extracted in step 1, we ranked the areas in the matrix (condition vs complementary 


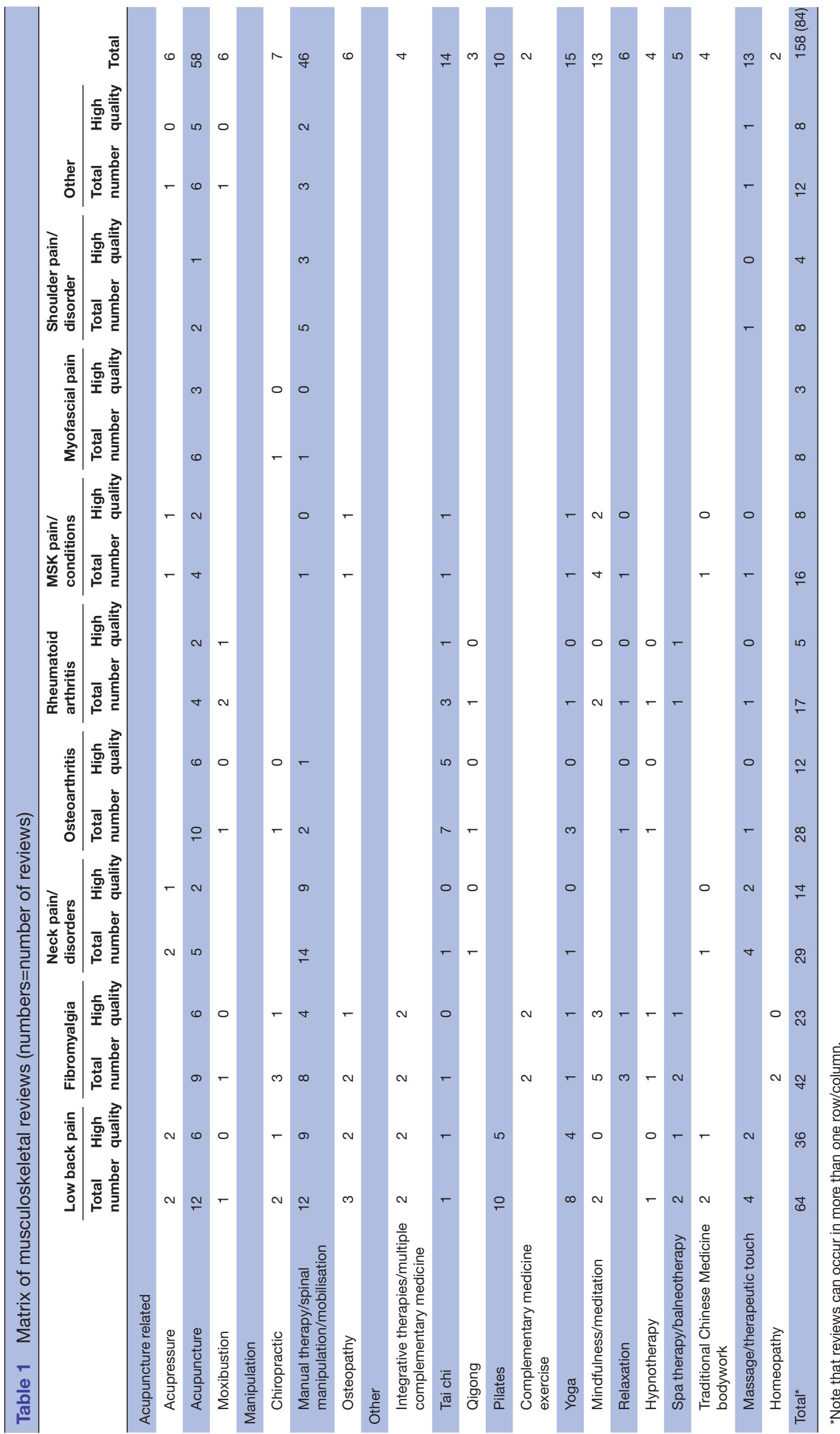

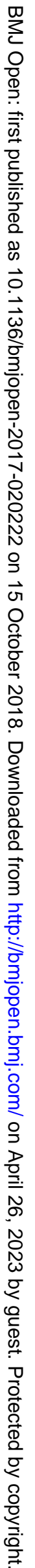


Table 2 Matrix of mental health reviews (numbers=number of reviews)

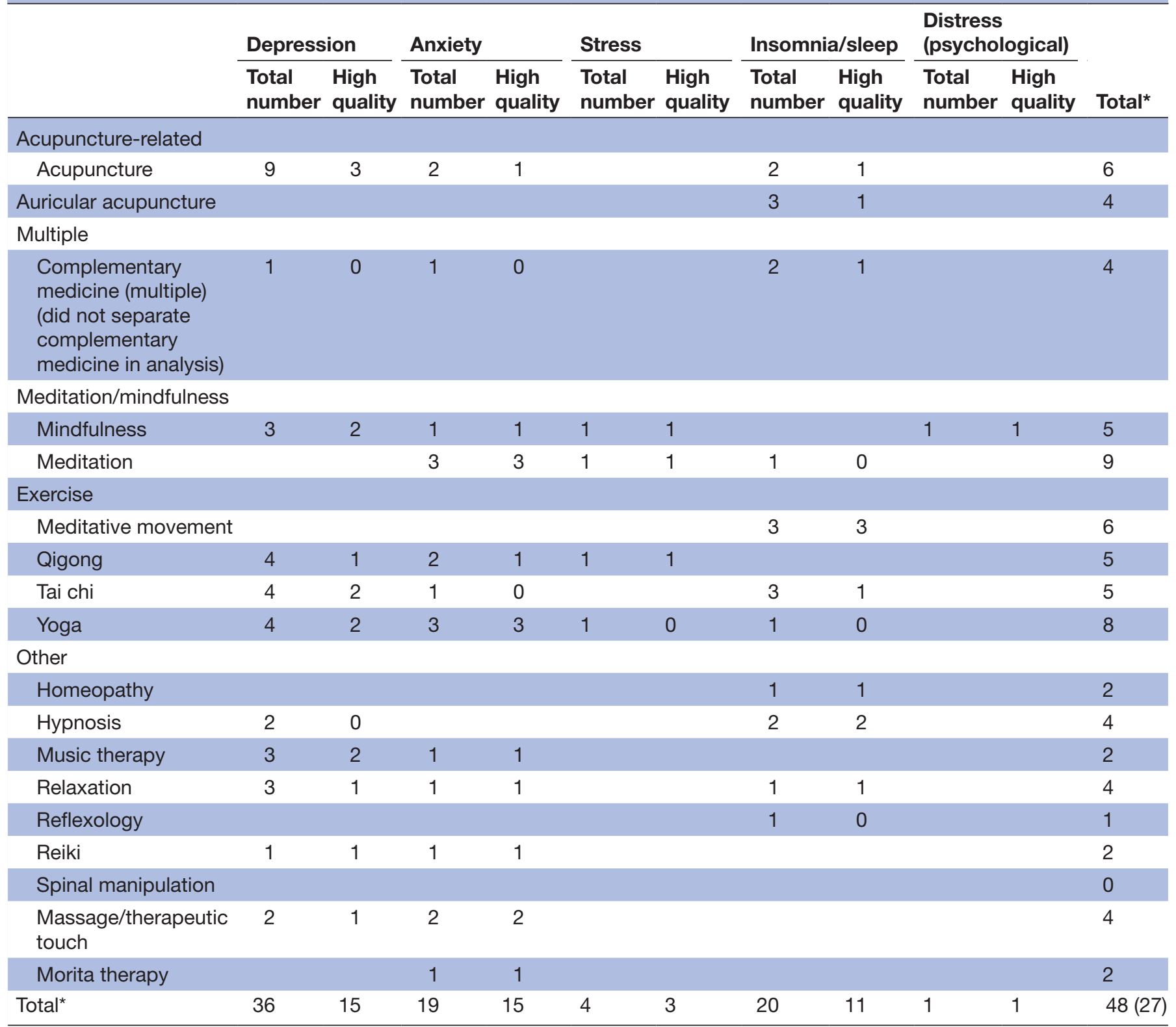

*Note that reviews can occur in more than one row/column

medicine), based on consideration of the following criteria:

1. Effectiveness: areas were ranked highly where there was enough moderate/good quality evidence to establish proof of concept, but still key gaps. Data on effectiveness came from the conclusions of the prioritised SRs regarding effectiveness and quality.

2. Safety: areas where there was evidence of harm were ranked lower.

3. Cost: areas where there was any indication that the intervention may have potential for cost-effectiveness were ranked highly.

4. Comorbidity: any interventions that showed an indication (of any quality) for comorbid MH and MSK patients were ranked highly.

\section{Step 3 sample size}

Once a ranked list of areas had been compiled, information on total sample size for the prioritised SR/s (ie, total number of participants in the trials included in the $\mathrm{SR} / \mathrm{s}$ ) was added to allow further discrimination, classified as: small ( $<500$ participants), medium (501 to $3000)$ or large $(>3000)$.

\section{Patient and public involvement}

The wider scoping study included a PPI group of seven people with experience of $\mathrm{MSK} / \mathrm{MH}$ issues, who advised the research team on a variety of issues as the study took shape and progressed. They met four times over the study period and provided input into the literature review questions, search strategy and selection criteria. 
The PPI group also provided ideas on ways to disseminate the findings to the general public and to patient groups.

\section{RESULTS}

\section{Search results}

Figure 1 shows the Preferred Reporting Items for Systematic Reviews and Meta-Analyses flowchart of the searches. ${ }^{39}$ Searches resulted in 8393 references-4304 for MH and 4089 for MSK, plus three for MH identified elsewhere (email update sent by journal publisher). After removing duplicates, Cochrane reviews which were withdrawn, Cochrane reviews which had been updated or those not in English, 5230 records remained for title screening. This resulted in $486 \mathrm{MH}$ and 739 MSK records for the abstract screening phase. We then excluded 49 (13 MH and 36 MSK) records, that is, editorials, commentaries, abstracts etc. After abstract screening, there remained 444 studies (180 MH and $264 \mathrm{MSK}$ ). At this stage, a further 12 records were added-three from grey literature (Prospero/Sigle/HSRProj), five from conference abstracts and four from the reference lists of overviews of SRs and other key reports. This produced 456 records to be screened at the full-text stage, after which 206 records remained: $48 \mathrm{MH}, 158 \mathrm{MSK}$.

During screening at the title stage (AL and DS), there were 49 disagreements (out of 4411 records; 1\%). During abstract screening (AL and each of the six authors), there were a total of 296 initial disagreements (out of 1165 records; $25 \%$ ). Most were resolved by discussion without requiring a third reviewer.

Of the 158 MSK SRs, 84 were included as high quality (scored six or more on AMSTAR): $\mathrm{LBP}^{40-69}$ fibromyalgia,${ }^{70-81}$ neck pain, ${ }^{40}{ }^{82-90} \mathrm{OA},{ }^{91-101}$ rheumatoid arthritis, ${ }^{97}$ 102-105 general MSK pain/conditions, ${ }^{106-110}$ shoulder pain/disorders, ${ }^{111-115}$ myofascial trigger point pain $^{106} 116117$ and other musculoskeletal (MSK) conditions. ${ }^{106} 118-123$

The 158 reviews covered 17 different and 15 different disorders. The overall matrix is shown below in table 1 . LBP was by far the most common topic, addressed by $64 / 158(40 \%)$ of reviews. Fibromyalgia was the next most common, followed by OA then neck pain/disorders. Acupuncture was the most common complementary medicine studied (58/158 SRs; 37\%), followed by manual therapy (including manipulation and mobilisation). The mean AMSTAR score for methodological quality of MSK reviews was 6/11 (ranging from 0 to 11). Online supplementary appendix 3 shows which items on the AMSTAR checklist were reported by the reviews.

Of the 48MHSRs, 27 were high quality (scored six or more on AMSTAR): depression, ${ }^{124-134}$ anxiety, ${ }^{124} 125129133$ 135-142 sleep, ${ }^{143-150}$ stress ${ }^{124} 125140$ and other. ${ }^{124}$ The 48 reviews covered 18 different and five different categories of MH symptom or disorder. The overall matrix is shown in table 2. Many of the reviews included more than one $\mathrm{MH}$ condition. Of the 48 reviews, $36(75 \%)$ included depression. Meditation, yoga, acupuncture and meditative movement were the most common complementary medicine. Online supplementary appendix 3 shows which items on the AMSTAR checklist were reported by the reviews.

The following sections present a summary of the areas where we found moderate/good quality evidence of effectiveness (from the prioritised SRs). For those conditions with evidence for more than one intervention, we have presented the results in tables.

\section{Evidence for MSK disorders}

The areas where there was moderate/good quality evidence were LBP, myofascial trigger point pain, OA, neck pain, fibromyalgia and lateral epicondylitis. It should be noted that the SR quality of evidence is based on the overall assessment of quality of the included RCTs by the SR authors, which is subject to some limitations.

\section{Low back pain}

Moderate/good quality evidence for LBP (see table 3) was found as follows:

- Yoga: four high-quality reviews, ${ }^{51}$ 60-62 one prioritised ${ }^{62}$

- Osteopathy: two high-quality reviews, ${ }^{64} 65$ one prioritised $^{65}$

- Acupuncture: six high-quality reviews, ${ }^{40} 4149505354$ two prioritised-as highest quality ${ }^{40}$ and most recent ${ }^{50}$

- Spinal manipulation/mobilisation: nine high-quality reviews, ${ }^{40-48}$ three prioritised (due to differences in types of back pain and interventions included $)^{404} 44$

- Spa/balneotherapy: one high-quality review ${ }^{52}$

- Tai chi: one high-quality review ${ }^{54}$

\section{Osteoarthritis}

Moderate/good quality evidence for OA (see table 4) was found as follows:

- Acupuncture: six high-quality reviews, ${ }^{91-96}$ two prioritised $^{92}$ as a Cochrane review and ${ }^{94}$ as most recent.

- Tai chi:five high-quality reviews, ${ }^{97-101}$ one prioritised $/{ }^{99}$

Neck pain

Moderate/good quality evidence for neck pain (see table 5) was found as follows:

- Manual therapy/manipulation: eight high-quality reviews, ${ }^{40} 82-88$ three were prioritised due to differing inclusion criteria. ${ }^{82} 8788$

- Acupuncture: two high-quality reviews, ${ }^{40} 89$ one prioritised. ${ }^{89}$

There was moderate quality evidence in a medium-sized population for a range of other techniques. ${ }^{82} 8788$

\section{Fibromyalgia}

Acupuncture for fibromyalgia was reviewed by-five high-quality reviews, ${ }^{70-7381}$ one prioritised. ${ }^{72}$ The prioritised review found moderate quality evidence in a small population compared with placebo for stiffness (acupuncture) and for pain and sleep disorders (electroacupuncture). However, there was some evidence that acupuncture is less effective than usual care for 


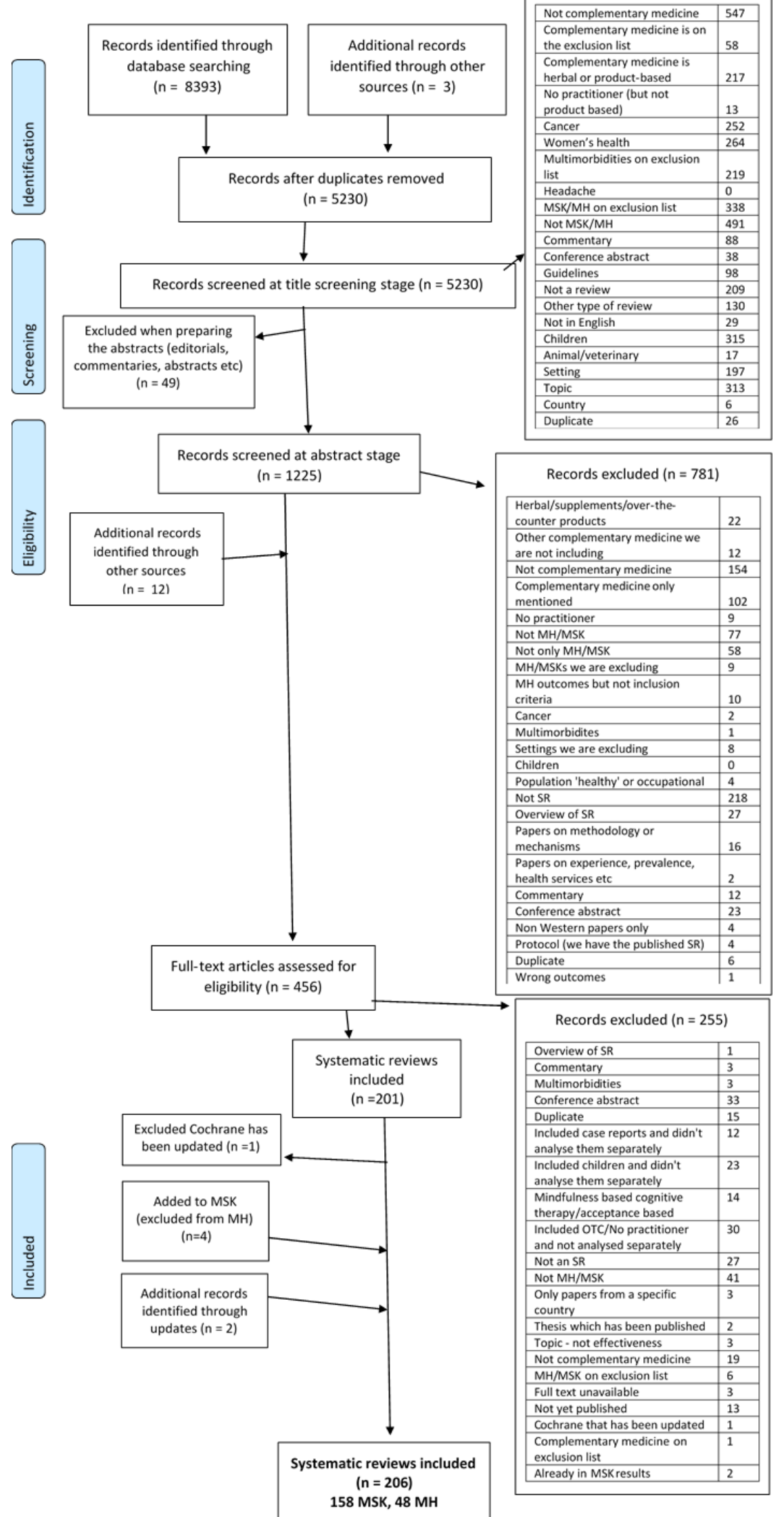

Figure 1 Preferred Reporting Items for Systematic Reviews and Meta-Analyses flowchart. MH, mental health; MSK, musculoskeletal; SR, systematic review. 
Table 3 Evidence for low back pain

\begin{tabular}{|c|c|c|c|c|c|}
\hline Comparator & Quality & $\begin{array}{l}\text { Population } \\
\text { size }\end{array}$ & Complementary medicine & Safety & Cost-effectiveness \\
\hline \multirow{4}{*}{$\begin{array}{l}\text { Active } \\
\text { intervention }\end{array}$} & Good & Medium & Osteopathy ${ }^{65}$ & Some evidence of harm ${ }^{65 *}$ & NR \\
\hline & Moderate & Large & $\begin{array}{l}\text { Spinal manipulation/ } \\
\text { mobilisation (chronic } \\
\text { only) }\end{array}$ & Some evidence of safety ${ }^{44} \dagger$ & $\begin{array}{l}\text { Mixed results-some } \\
\text { evidence of } C E^{47} \ddagger\end{array}$ \\
\hline & Moderate & Medium & Yoga $^{62}$ & Some evidence of safety ${ }^{516062} \S$ & No data \\
\hline & Moderate & Small & Balneotherapy ${ }^{52}$ & Some evidence of safety ${ }^{52}$ & NR \\
\hline \multirow[t]{3}{*}{ Usual care } & Moderate & Large & $\begin{array}{l}\text { Acupuncture } 4050 \text { (for pain, } \\
\text { function, well-being, disability, } \\
\text { range of movement, quality } \\
\text { of life) }\end{array}$ & Some evidence of safety ${ }^{5354}$ & $\begin{array}{l}\text { Some evidence of } \\
\mathrm{CE}^{40 \star \star}\end{array}$ \\
\hline & Moderate & Small & Spa therapy ${ }^{52}$ & Some evidence of safety ${ }^{52}+\dagger$ & NR \\
\hline & & & Tai chi $^{54}$ & NR & NR \\
\hline Placebo & Moderate & Large & $\begin{array}{l}\text { Acupuncture (for pain and } \\
\text { quality of life; negative } \\
\text { evidence for disability). }\end{array}$ & Some evidence of safety ${ }^{5354}$ & $\begin{array}{l}\text { Some evidence of } \\
\mathrm{CE}^{40 * \star}\end{array}$ \\
\hline
\end{tabular}

*Two studies reported minor adverse events.

†One review identified serious adverse events, but this appeared unrelated to treatment. Minor adverse events included muscle soreness, stiffness and/or transient increase in pain.

$\ddagger$ Mixed results regarding cost-effectiveness, ${ }^{40}$ with limited evidence that manual therapy is more cost-effective than usual care. ${ }^{47}$

$\S$ No serious adverse events associated with the yoga.

१5\% minor adverse events and no serious adverse events.

${ }^{*}$ Short-term only.

$\dagger †$ No adverse events from one study.

CE, cost effectiveness; NR, not reported (by systematic reviews).

MH outcomes in fibromyalgia. ${ }^{72}$ There is some evidence of safety (no serious adverse events) ${ }^{70-7381}$ but none of cost-effectiveness.

\section{Myofascial trigger point pain}

Acupuncture for myofascial trigger point pain was reviewed by-three high-quality reviews. ${ }^{106} 116117$ The prioritised review found good quality evidence in a medium-sized population compared with placebo and other active interventions for pain in the short and medium term but not in the long term. ${ }^{117}$ However, safety, cost-effectiveness or impact on MH outcomes were not reported. ${ }^{106116117}$

\section{Lateral epicondylitis}

One high-quality review ${ }^{120}$ found moderate quality evidence for manual therapy (mobilisation with movement) but the comparator and sample size were not reported so we are unable to include it in our synthesis.

\section{Evidence for mental health}

No reviews provided good quality evidence for complementary medicine for any MH condition nor any evidence of cost-effectiveness, mainly because the latter was not reported.

\section{Depression}

Moderate quality evidence for depression (see table 6) was found as follows:

- Mindfulness/meditation: two high-quality reviews, ${ }^{124} 125$ both prioritised as included different types of meditation/mindfulness/mindfulness-based stress reduction (MBSR) or populations.

Table 4 Evidence for osteoarthritis

\begin{tabular}{|c|c|c|c|c|c|}
\hline Comparator & Quality & $\begin{array}{l}\text { Population } \\
\text { size }\end{array}$ & Complementary medicine & Safety & Cost-effectiveness \\
\hline Placebo & Good & Large & Acupuncture ${ }^{9294 \star}$ & Some evidence of harm ${ }^{9192} \dagger$ & NR \\
\hline
\end{tabular}

${ }^{*}$ Compared to pulsed electromagnetic fields, muscle-strengthening or aerobic exercise, weight loss.

†Up to $45 \%$ frequency of minor adverse events.

¥Only in the short term.

§Systematic reviews (SRs) concluded tai chi is safe.

NR, not reported (by SRs). 
Table 5 Evidence for neck pain

\begin{tabular}{|c|c|c|c|c|c|}
\hline Comparator & Quality & $\begin{array}{l}\text { Population } \\
\text { size }\end{array}$ & $\begin{array}{l}\text { Complementary } \\
\text { medicine }\end{array}$ & Safety & Cost-effectiveness \\
\hline \multirow{3}{*}{$\begin{array}{l}\text { Active } \\
\text { intervention }\end{array}$} & Good & Medium & Manual therapy ${ }^{87 \star}$ & Some evidence of potential harm ${ }^{82}{ }^{83} \dagger$ & Some evidence of $\mathrm{CE}^{8788} \ddagger$ \\
\hline & Moderate & Large & Manipulation ${ }^{82} \S \rrbracket$ & Some evidence of potential harm ${ }^{82}{ }^{83} \dagger$ & Some evidence of $\mathrm{CE}^{8788} \ddagger$ \\
\hline & Moderate & Small & Manual therapy ${ }^{88 * *}$ & Some evidence of potential harm ${ }^{82}{ }^{83} \dagger$ & Some evidence of $\mathrm{CE}^{87}{ }^{88} \ddagger$ \\
\hline Placebo & Moderate & Medium & Acupuncture $^{89}$ & Some evidence of safety ${ }^{89}$ & No data ${ }^{40}$ \\
\hline Usual care & Moderate & Medium & Acupuncture ${ }^{89}$ & Some evidence of safety ${ }^{89}$ & No data ${ }^{40}$ \\
\hline
\end{tabular}

*Manual therapy plus exercise compared with exercise alone.

†Reduced cost of therapy.

¥Minor adverse events and rare but devastating adverse effects from manipulation.

§Compared to medication.

ПAlso showed effectiveness for pain compared with any control.

${ }^{* *}$ Mobilisation, manipulation and soft tissue techniques.

CE, cost effectiveness.

- Tai chi: two high quality reviews, ${ }^{132} 134$ both prioritised as Chi et $a l^{134}$ only reviewed studies of older people (Liu $e t a l^{132}$ found only poor quality evidence).

- Relaxation: one high-quality review ${ }^{129}$ but comparator and sample size were not reported so it is not included here.

Anxiety

Moderate quality evidence for anxiety (see table 7) was found as follows:

- Meditation, including moving meditation (yoga, tai chi and qi gong): three high-quality reviews, ${ }^{125} 137138$ one prioritised. ${ }^{138}$

- MBSR: one high-quality review. ${ }^{124}$

- Yoga: three high-quality reviews, ${ }^{129} 135136$ one prioritised. ${ }^{136}$

Sleep disorders

Three high-quality reviews considered meditative/ mind-body movement for sleep. ${ }^{143-145}$ The prioritised review found moderate quality evidence in older adults for meditative movement in a medium-sized population, compared with usual care and other active interventions. ${ }^{143}$ There was some evidence of safety (no adverse events) ${ }^{143}$ and effect on sleep quality in an MSK population. ${ }^{145}$ No cost-effectiveness data reported.

\section{Stress and distress}

There was one high-quality review of mindfulness for stress and distress. ${ }^{124}$ For stress, they found moderate quality evidence in a medium-sized population compared with usual care and placebo, and some evidence of effectiveness on stress as an outcome in an MSK population. ${ }^{124}$ There were no data on cost-effectiveness and no data on safety. For distress, they found moderate quality evidence in a medium-sized population compared with usual care, and some evidence of effectiveness on distress as an outcome in an MSK population. ${ }^{124}$ There were no data on cost-effectiveness and safety was not reported.

There was only poor quality evidence for all other combinations of $\mathrm{MH}$ condition/complementary medicine/ comparator.

\section{Evidence for effectiveness in comorbidity/MH outcomes in MSK}

Only one SR provided data on comorbid MSK and MH conditions (depression and a variety of comorbid MSK conditions). ${ }^{132}$ Three SRs provided data on MH outcomes in MSK populations (but did not specify an MH score/ diagnosis as inclusion criterion). Tai chi for depression and comorbid conditions (including MSKs) may be less effective than for depression alone ${ }^{132}$; MBSR/meditation

\begin{tabular}{|c|c|c|c|c|c|}
\hline Comparator & Quality & $\begin{array}{l}\text { Population } \\
\text { size }\end{array}$ & Complementary medicine & Safety & $\begin{array}{l}\text { Cost- } \\
\text { effectiveness }\end{array}$ \\
\hline Active intervention & Moderate & Medium & Meditation ${ }^{125 *}$ & $\begin{array}{l}\text { Some evidence of safety§ } \\
125\end{array}$ & No data ${ }^{124}$ \\
\hline \multirow[t]{2}{*}{ Usual care } & Moderate & Medium & $\begin{array}{l}\text { MBSR (mindfulness-based } \\
\text { stress reduction) }^{124 *}\end{array}$ & $\begin{array}{l}\text { Some evidence of safety§ } \\
125\end{array}$ & No data ${ }^{124}$ \\
\hline & Moderate & Medium & Tai chi $i^{134}+\ddagger$ & No data ${ }^{134}$ & No data ${ }^{134}$ \\
\hline
\end{tabular}

${ }^{*}$ Also some evidence of effectiveness for both in musculoskeletal (MSK) populations. ${ }^{124} 125$ †Older adults only.

¥May be less effective in comorbid populations (including some MSK conditions). ${ }^{132}$

$\S$ Nine trials found no adverse events. 


\begin{tabular}{|c|c|c|c|c|}
\hline Quality & Population size & $\begin{array}{l}\text { Complementary } \\
\text { medicine }\end{array}$ & Safety & $\begin{array}{l}\text { Cost- } \\
\text { effectiveness }\end{array}$ \\
\hline Moderate & Medium & Yoga $^{136} \ddagger$ & No data ${ }^{135}$ & NR \\
\hline Moderate & Medium & Meditation ${ }^{138_{*}} \dagger$ & Some evidence of safety ${ }^{125137138}$ & NR \\
\hline
\end{tabular}

*Moving meditation (tai chi, qi gong or yoga) was more effective than static meditation.

†Mindfulness-based stress reduction (MBSR)/meditation was also effective for anxiety (as an outcome) in a musculoskeletal population. ${ }^{124} 125$ ¥For women with breast cancer only.

$\mathrm{NR}$, not reported (by systematic reviews).

was effective for MH outcomes (depression, anxiety, stress/distress) in an MSK population ${ }^{124}{ }^{125}$; meditative/ mind-body movement was effective for sleep outcomes in an MSK population. ${ }^{145}$

\section{Complementary medicine with evidence for both MSK and MH conditions}

From the above synthesis, complementary medicine with moderate/good quality evidence for both MSK and MH conditions (from separate SRs) are yoga and tai chi. Yoga appears to be effective for both LBP and anxiety compared with other active interventions, although the anxiety finding was only from studies of women with breast cancer. Meditative movement, which includes yoga, is effective for sleep disorders, although only for older adults (there is also some evidence in chronic pain and fibromyalgia populations). Tai chi appears to be effective compared with usual care for LBP, knee OA and depression, in older people (although it appears less effective in comorbid depressed patients). Meditative movement, which includes tai chi, is effective for sleep disorders, although only for older adults (there is some evidence in chronic pain and fibromyalgia populations as well).

\section{Update}

Since completing this review, in July 2017, we searched for recent SRs on the highest ranking topics (results are not included in tables 3-7). These either provide additional evidence for $\mathrm{MH}$ outcomes in an MSK population, or evidence supporting our original conclusions.

- Yoga: a new Cochrane review for LBP has been published which suggests there is moderate-quality evidence for yoga compared with other active interventions for pain, and for function at 6 months only, although they also found moderate-quality evidence of harm for yoga (primarily exacerbation of back pain). ${ }^{151}$ They also found very low-quality MH evidence for yoga improving depression (as an outcome not a diagnosis) in LBP (comparator not stated). ${ }^{151}$

- MBSR/mindfulness/meditation: a new SR provides evidence for mindfulness and $\mathrm{MH}$, including highquality evidence (sample size not reported) for mindfulness helping with depression (compared with all controls-usual care, and active interventions (education, stress management); (as an outcome not a diagnosis) in LBP (and fibromyalgia). ${ }^{152}$ Another SR of mindfulness for LBP was recently published but cannot be included as there were no conclusions regarding study quality. ${ }^{153}$

- Acupuncture (compared with other active interventions): Two new SRs confirm the effectiveness of acupuncture for OA of the knee, with moderate-quality evidence in a large sample compared with active interventions and placebo. ${ }^{154} 155$

\section{DISCUSSION}

This scoping review has highlighted the large and increasing number of SRs of complementary medicine for MSK and MH disorders, covering 29 different complementary medicine approaches, but identified no high-quality evidence for complementary medicine for MSK-MH comorbid populations. Three reviews showed that MBSR/meditation/meditative movement may improve MH outcomes in MSK populations. Acupuncture, yoga, tai chi and mindfulness/meditation have evidence for both MSK and MH conditions.

We have identified moderate/good-quality evidence (as reported by SR authors) for effectiveness (any comparator) in a moderate/large population for: LBP (yoga, acupuncture, spinal manipulation/mobilisation, osteopathy), OA (acupuncture, tai chi), neck pain (acupuncture, manipulation/manual therapy), myofascial trigger point pain (acupuncture), depression (MBSR, meditation, tai chi, relaxation), anxiety (meditation/MBSR, moving meditation, yoga), sleep disorders (meditative/mind-body movement) and stress/ distress (mindfulness). The majority of these complementary approaches had some evidence of safetyonly three had evidence of harm-osteopathy for LBP, acupuncture for $\mathrm{OA}$ and manipulation/manual therapy for neck pain. There was some evidence of cost-effectiveness for spinal manipulation/mobilisation and acupuncture for LBP, and manual therapy/manipulation for neck pain, but few SRs reviewed cost-effectiveness and many found no data. 
Regarding comorbidity, from our original searches, the only evidence for MH outcomes in an MSK population (not necessarily with MH conditions) was for MBSR/ meditation/meditative movement/mindfulness. Tai chi and yoga were effective for MSK and MH conditions in separate SRs (not comorbid populations). Our 2017 update found new (but poor quality) evidence for yoga in MSK-MH comorbidity and more evidence for mindfulness in MSK-MH comorbidity.

Some of these studies showed effectiveness compared with an active comparator (spinal manipulation/mobilisation and yoga for LBP; meditation for depression and anxiety), providing some evidence that these interventions have effects over and above non-specific attention.

The quality of the SRs was very variable. We used a quality tool, AMSTAR, which itself has some limitations, as it includes both methodological and reporting items which are not all necessarily equal in importance, and some of which can be difficult to interpret. Future reviews may consider prioritising certain items on AMSTAR, using the new version of AMSTAR, ${ }^{156}$ or using an alternative critical appraisal tool such as the Oxford Centre for Evidence-based Medicine checklist (https://www. cebm.net/2014/06/critical-appraisal/). An assessment of risk of bias, using, for example, Risk Of Bias In Systematic reviews (ROBIS), may be useful in addition to these quality assessments.

The quality of included trials also varied greatly; it is notable that none of the MH SRs concluded that trial quality was 'good' overall. In addition, assessment of individual RCT study quality is likely to have varied between SR authors, a common issue with complementary medicine studies which rarely fit conventional quality criteria (particularly blinding). Very few of the MSK SRs and none of the MH SRs mentioned cost-effectiveness. Safety was rarely adequately reported in SRs or the studies they included. Future SRs in the areas of complementary medicine and MSK/MH need to ensure they include a priori design/protocol registration, a list of excluded studies and conflict of interest statements, and use duplicate study selection and data extraction, assess publication bias and search for grey literature.

Both a strength and limitation of this scoping review was its comprehensive scope which included a wide range of complementary medicine approaches and types of MSK and MH condition, but limited the depth of analysis and discussion.

Other key strengths were the systematic searching techniques, prioritising high-quality SRs using MeSH terms where possible, and search techniques to capture grey and unpublished literature. The whole project team was involved in independently screening the literature search results, although a limitation was that only one author conducted data extraction. We included a quality appraisal of the reviews, although time constraints meant this was an abbreviated assessment. One of the key limitations was the pragmatic decision to only include SRs, which may have led to the exclusion of some complementary medicines, and means results are subject to the limitations of SR and trial methodology, study designs which are sometimes challenging for complementary medicine. ${ }^{157-159}$ Another key limitation is our definition of complementary medicine as including a practitioner in its delivery (which relied on review authors reporting these details), which excluded over-the -counter products or self-care practices, herbal medicine in particular, but was necessary to limit the scope of the review to complementary medicine which may be appropriate for an integrated care model using referral from a general practitioner. We are aware that by excluding reviews published pre-2005, we may have excluded some topics. We were unable to include non-English publications.

Although complementary medicine is commonly used by patients in the $\mathrm{UK},{ }^{25}$ it is not widely available via the NHS. Given the high burden of MSK and MH conditions to individuals and society in the UK, and the prevalence of comorbidity, complementary medicine may be worth considering for some patients, where there is evidence of effectiveness, cost-effectiveness and safety.

One of the main aims of this study was to inform the design of a future trial to assess the effectiveness and cost-effectiveness of an integrated medicine approach for patients with comorbid MSK and MH disorders. We will combine the results of this review with the views of conventional and complementary medicine practitioners, the public and NHS providers, to inform the final focus for an RCT. Our proposed trial would be pragmatic and focus on overall effectiveness, so interventions with evidence compared with any comparator are potential candidates.

SRs of complementary medicine consistently conclude that further high-quality trials are needed, with longer follow-up and larger sample sizes, assessing cost-effectiveness and use of appropriate, sensitive, validated outcome measures.

Based on our criteria of study quality, safety, cost-effectiveness and evidence for MSK MH comorbidity, this scoping review suggests that the most promising complementary medicine for future research in the area of MHMSK comorbidity are: mindfulness (evidence for MH in MSK populations and evidence of safety), yoga (evidence for MSK and MH conditions) and tai chi (evidence for MSK and MH conditions, evidence of safety). The comorbid populations that would benefit most are less clear, as so few reviews focus on comorbidity, but may include LBP, OA, depression, anxiety and sleep.

Acknowledgements We are grateful to Catherine Borwick for her help with literature searching and Sandra Hollinghurst for her help with screening the papers. We are also very grateful to our PPI group.

Contributors AL conducted all literature searches, data extraction and quality appraisal, with the project team (GF, HM, PL, SWM and DS) all screening papers for inclusion. The team (GF, HM, PL, SWM and DS) all provided input into the inclusion/ exclusion criteria. DS advised on the review process. GF, HM, PL, SWM and DS were all involved in the prioritisation of topics from the review results. AL drafted the paper and all authors reviewed and edited it. 
Funding The report is based on independent research commissioned and funded by the NIHR Policy Research Programme (The Effectiveness And Cost Effectiveness Of Complementary And Alternative Medicine (Cam) For Multimorbid Patients With Mental Health And Musculoskeletal Problems In Primary Care In The UK: A Scoping Study).

Disclaimer The views expressed in the publication are those of the author(s) and not necessarily those of the NHS, the NIHR, the Department of Health, 'arms' length bodies or other government departments.

Competing interests None declared.

Patient consent Not required.

Provenance and peer review Not commissioned; externally peer reviewed.

Data sharing statement We are able to provide copies of searches and lists of excluded references on request.

Open access This is an open access article distributed in accordance with the Creative Commons Attribution Non Commercial (CC BY-NC 4.0) license, which permits others to distribute, remix, adapt, build upon this work non-commercially, and license their derivative works on different terms, provided the original work is properly cited, appropriate credit is given, any changes made indicated, and the use is non-commercial. See: http://creativecommons.org/licenses/by-nc/4.0/.

\section{REFERENCES}

1. Murray CJL, Richards MA, Newton JN, et al. UK health performance: findings of the Global Burden of Disease Study 2010. Lancet 2013;381:997-1020.

2. Department of Health, 2006. The Musculoskeletal Services Framework Y1. Secondary The Musculoskeletal Services Framework Y1. http://webarchive.nationalarchives.gov.uk/ 20130107105354/http:/www.dh.gov.uk/prod_consum_dh/groups/ dh digitalassets/@dh/@en/documents/digitalasset/dh 4138412.pd

3. . Centre HSCl, et a/ln: Sally McManus HM, Brugha T, Bebbington $\mathrm{P}$, Jenkins R, . eds. Adult psychiatric morbidity in England, 2007: results of a household survey, 2009.

4. Halliwell E, Main L, Richardson C. The fundamental facts. Secondary the fundamental facts 2007. http://www.mentalhealth. org.uk/content/assets/PDF/publications/fundamental_facts_2007. pdf?view=Standard

5. World Health Organization, 2013. Chronic diseases and health promotion: chronic rheumatic conditions. Secondary Chronic diseases and health promotion: chronic rheumatic conditions. http://www.who.int/chp/topics/rheumatic/en/

6. Health and Safety Executive, 2012. Annual Statistics Report 201112. Secondary Annual Statistics Report 2011-12. http://www.hse. gov.uk/statistics/overall/hssh1112.pdf

7. HM Government. No health without mental health: a crossgovernment mental health outcomes strategy for people of all ages. Secondary no health without mental health: a crossgovernment mental health outcomes strategy for people of all ages 2011. https://www.gov.uk/government/uploads/system/uploads/ attachment_data/file/213761/dh_124058.pdf.

8. Dionne CE, Dunn KM, Croft PR. Does back pain prevalence really decrease with increasing age? A systematic review. Age Ageing 2006;35:229-34.

9. Jeffries LJ, Milanese SF, Grimmer-Somers KA. Epidemiology of adolescent spinal pain: a systematic overview of the research literature. Spine 2007;32:2630-7.

10. Hoy D, Bain C, Williams G, et al. A systematic review of the global prevalence of low back pain. Arthritis Rheum 2012;64:2028-37.

11. Maniadakis N, Gray A. The economic burden of back pain in the UK. Pain 2000;84:95-103.

12. National Institute for Health and Clinical Excellence. Low back pain final scope. Secondary low back pain final scope 2007. https:// www.nice.org.uk/guidance/cg88/documents/low-back-pain-finalscope 2

13. Arthritis Research UK. Osteoarthritis in general practice. Secondary Osteoarthritis in general practice 2013. http://www. arthritisresearchuk.org/ /media/Files/Policy\%20files/Policy\% 20pages\%20files/Keel_Data_Report_digital_output.ashx?la=en

14. Oxford Economics. The economic costs of arthritis for the UK economy. Secondary the economic costs of arthritis for the UK economy 2010. http://www.oxfordeconomics.com/my-oxford/ projects/128882

15. Centre HSCl. Health Survey for England 2014: health, social care and lifestyles - Summary of key findings. Secondary health survey for England 2014: health, social care and lifestyles - summary of key findings 2014. http://www.hscic.gov.uk/catalogue/PUB19295/ HSE2014-Sum-bklet.pdf

16. Ohayon MM. Epidemiology of insomnia: what we know and what we still need to learn. Sleep Med Rev 2002;6:97-111.

17. Salisbury C, Johnson L, Purdy S, et al. Epidemiology and impact of multimorbidity in primary care: a retrospective cohort study. $\mathrm{Br} J$ Gen Pract 2011;61:e12-e21.

18. Violan C, Foguet-Boreu Q, Flores-Mateo G, et al. Prevalence, determinants and patterns of multimorbidity in primary care: a systematic review of observational studies. PLoS One 2014;9:e102149.

19. Mercer S, Salisbury C, Fortin M. ABC of Multimorbidity: John Wiley \& Sons, 2014

20. Barnett K, Mercer SW, Norbury M, et al. Epidemiology of multimorbidity and implications for health care, research, and medical education: a cross-sectional study. Lancet 2012;380:37-43.

21. Katona C, Peveler R, Dowrick C, et al. Pain symptoms in depression: definition and clinical significance. Clin Med 2005;5:390-5.

22. Fisher P. Connecting with the Strategic Agenda: integrated medicine, polypharmacy, antimicrobial resistance and multimorbidity CAMSTRAND 2015.

23. The House of Lords. What is complementary and alternative medicine? Growing use of CAM in the United Kingdom science and technology - sixth report, 2000.

24. Eardley S, Bishop FL, Prescott P, et al. A systematic literature review of complementary and alternative medicine prevalence in EU. Forsch Komplementmed 2012;19(Suppl 2):18-28.

25. Hunt KJ, Coelho HF, Wider B, et al. Complementary and alternative medicine use in England: results from a national survey. Int $\mathrm{J}$ Clin Pract 2010;64:1496-502.

26. Wye L, Shaw A, Sharp D. Designing a 'NHS friendly' complementary therapy service: a qualitative case study. BMC Health Serv Res 2008;8:173.

27. Fisher $\mathrm{P}$, van Haselen $\mathrm{R}$, Hardy $\mathrm{K}$, et al. Effectiveness gaps: a new concept for evaluating health service and research needs applied to complementary and alternative medicine. J Altern Complement Med 2004:10:627-32.

28. Unwin J, Peters D. Gatekeepers and the Gateway--a mixedmethods inquiry into practitioners' referral behaviour to the Gateway Clinic. Acupunct Med 2009;27:21-5.

29. Kessler RC, Soukup J, Davis RB, et al. The use of complementary and alternative therapies to treat anxiety and depression in the United States. Am J Psychiatry 2001;158:289-94.

30. Mamtani R, Cimino A. A primer of complementary and alternative medicine and its relevance in the treatment of mental health problems. Psychiatr Q 2002;73:367-81.

31. Artus $M$, Croft $P$, Lewis $M$. The use of CAM and conventional treatments among primary care consulters with chronic musculoskeletal pain. BMC Fam Pract 2007;8:26.

32. Arksey H, O'Malley L. Scoping studies: towards a methodological framework. Int J Soc Res Methodol 2005;8:19-32.

33. Mays N, Roberts E, Popay E. Chapter 12: synthesising research evidence. Methods for studying the delivery and organisation of health services. London: Routledge, 2001:188-220.

34. Levac D, Colquhoun H, O'Brien KK. Scoping studies: advancing the methodology. Implement Sci 2010;5:69.

35. Daudt HM, van Mossel C, Scott SJ. Enhancing the scoping study methodology: a large, inter-professional team's experience with Arksey and O'Malley's framework. BMC Med Res Methodol 2013;13:48.

36. Colquhoun $\mathrm{HL}$, Levac D, O'Brien KK, et al. Scoping reviews: time for clarity in definition, methods, and reporting. $J$ Clin Epidemiol 2014;67:1291-4.

37. Pham MT, Rajić A, Greig JD, et al. A scoping review of scoping reviews: advancing the approach and enhancing the consistency. Res Synth Methods 2014;5:371-85.

38. Shea BJ, Hamel C, Wells GA, et al. AMSTAR is a reliable and valid measurement tool to assess the methodological quality of systematic reviews. J Clin Epidemiol 2009;62:1013-20.

39. Moher D, Liberati A, Tetzlaff J, et al. PRISMA Group. Preferred reporting items for systematic reviews and meta-analyses: the PRISMA statement. BMJ 2009;339:b2535.

40. Furlan AD, Yazdi F, Tsertsvadze A, et al. Complementary and alternative therapies for back pain II. Evid Rep Technol Assess 2010;194:1-764.

41. Rubinstein SM, van Middelkoop M, Kuijpers T, et al. A systematic review on the effectiveness of complementary and alternative medicine for chronic non-specific low-back pain. Eur Spine $J$ 2010;19:1213-28. 
42. Dagenais S, Gay RE, Tricco AC, et al. NASS Contemporary Concepts in Spine Care: spinal manipulation therapy for acute low back pain. Spine J 2010;10:918-40.

43. Rubinstein SM, van Middelkoop M, Assendelft WJ, et al. Spinal manipulative therapy for chronic low-back pain: an update of a Cochrane review. Spine 2011;36:E825-46.

44. Rubinstein SM, Terwee CB, Assendelft WJ, et al. Spinal manipulative therapy for acute low-back pain. Cochrane Database Syst Rev 2012;170:CD008880.

45. Merepeza A. Effects of spinal manipulation versus therapeutic exercise on adults with chronic low back pain: a literature review. J Can Chiropr Assoc 2014;58:456-66.

46. Hidalgo B, Detrembleur C, Hall T, et al. The efficacy of manual therapy and exercise for different stages of non-specific low back pain: an update of systematic reviews. J Man Manip Ther 2014;22:59-74.

47. Tsertsvadze A, Clar C, Court R, et al. Cost-effectiveness of manual therapy for the management of musculoskeletal conditions: a systematic review and narrative synthesis of evidence from randomized controlled trials. J Manipulative Physiol Ther 2014:37:343-62.

48. Franke H, Fryer G, Ostelo RW, et al. Muscle energy technique for non-specific low-back pain. Cochrane Database Syst Rev 2015:2:CD009852.

49. Manheimer E, White A, Berman B, et al. Meta-analysis: acupuncture for low back pain[correction appears in Ann Intern Med 2005 Jun 7;142(11):950-1; Ann Intern Med 2005;143(9):695]. Ann Intern Med 2005;142:651

50. Xu M, Yan S, Yin X, et al. Acupuncture for chronic low back pain in long-term follow-up: a meta-analysis of 13 randomized controlled trials. Am J Chin Med 2013;41:1-19.

51. Holtzman S, Beggs RT. Yoga for chronic low back pain: a meta-analysis of randomized controlled trials. Pain Res Manag 2013:18:267-72.

52. Pittler MH, Karagülle MZ, Karagülle M, et al. Spa therapy and balneotherapy for treating low back pain: meta-analysis of randomized trials. Rheumatology 2006:45:880-4.

53. Furlan $A D$, van Tulder $M$, Cherkin $D$, et al. Acupuncture and dry-needling for low back pain: an updated systematic review within the framework of the cochrane collaboration. Spine 2005;30:944-63.

54. Yuan QL, Guo TM, Liu L, et al. Traditional Chinese medicine for neck pain and low back pain: a systematic review and metaanalysis. PLoS One 2015;10:e0117146.

55. Posadzki P, Lizis P, Hagner-Derengowska M. Pilates for low back pain: a systematic review. Complement Ther Clin Pract 2011;17:85-9.

56. Lim ECW, Poh RLC, Low AY, et al. Effects of Pilates-Based Exercises on Pain and Disability in Individuals With Persistent Nonspecific Low Back Pain: A Systematic Review With Metaanalysis.

J Orthop Sports Phys Ther 2011;41:70-80.

57. Miyamoto GC, Costa LO, Cabral CM. Efficacy of the Pilates method for pain and disability in patients with chronic nonspecific low back pain: a systematic review with meta-analysis. Braz $J$ Phys Ther 2013;17:517-32.

58. Aladro-Gonzalvo AR, Araya-Vargas GA, Machado-Díaz M, et al. Pilates-based exercise for persistent, non-specific low back pain and associated functional disability: a meta-analysis with metaregression. J Bodyw Mov Ther 2013;17:125-36.

59. Yamato TP, Maher CG, Saragiotto BT, et al. Cochrane Back and Neck Group. Pilates for low back pain. Cochrane Database Syst Rev 2015;37:CD010265.

60. Posadzki P, Ernst E. Yoga for low back pain: a systematic review of randomized clinical trials. Clin Rheumatol 2011;30:1257-62.

61. Ward L, Stebbings S, Cherkin D, et al. Yoga for functional ability, pain and psychosocial outcomes in musculoskeletal conditions: a systematic review and meta-analysis. Musculoskeletal Care 2013;11:203-17.

62. Cramer $\mathrm{H}$, Lauche $\mathrm{R}$, Haller $\mathrm{H}$, et al. A systematic review and metaanalysis of yoga for low back pain. Clin J Pain 2013;29:450-60.

63. Furlan AD, Giraldo M, Baskwill A, et al. Cochrane Back and Neck Group. Massage for low-back pain. Cochrane Database Syst Rev 2015;18. Art. No.: CD001929.

64. Orrock PJ, Myers SP. Osteopathic intervention in chronic nonspecific low back pain: a systematic review. BMC Musculoskelet Disord 2013;14:129.

65. Franke H, Franke JD, Fryer G. Osteopathic manipulative treatment for nonspecific low back pain: a systematic review and metaanalysis. BMC Musculoskelet Disord 2014;15:286.
66. Kim YC, Lee MS, Park E-S, et al. Acupressure for the Treatment of Musculoskeletal Pain Conditions: A Systematic Review. J Musculoskelet Pain 2012;20:116-21.

67. Hu XY, Chen NN, Chai QY, et al. Integrative treatment for low back pain: An exploratory systematic review and meta-analysis of randomized controlled trials. Chin J Integr Med 2015. Accepted for publication.

68. Kizhakkeveettil A, Rose K, Kadar GE. Integrative therapies for low back pain that include complementary and alternative medicine care: a systematic review. Glob Adv Health Med 2014;3:49-64.

69. Walker BF, French SD, Grant W, et al. Combined chiropractic interventions for low-back pain. Cochrane Database Syst Rev 2010;29:CD005427. N.PAG.

70. Langhorst J, Klose P, Musial F, et al. Efficacy of acupuncture in fibromyalgia syndrome--a systematic review with a meta-analysis of controlled clinical trials. Rheumatology 2010;49:778-88.

71. Cao H, Liu J, Lewith GT. Traditional Chinese Medicine for treatment of fibromyalgia: a systematic review of randomized controlled trials. J Altern Complement Med 2010;16:397-409.

72. Deare JC, Zheng Z, Xue CCL, et al. Acupuncture for treating fibromyalgia. Cochrane Database Syst Rev 2013;143:CD007070.

73. Yang B, Yi G, Hong W, et al. Efficacy of acupuncture on fibromyalgia syndrome: a meta-analysis. J Tradit Chin Med 2014:34:381-91.

74. Porter NS, Jason LA, Boulton A, et al. Alternative medical interventions used in the treatment and management of myalgic encephalomyelitis/chronic fatigue syndrome and fibromyalgia. $J$ Altern Complement Med 2010;16:235-49.

75. Li YH, Wang FY, Feng CQ, et al. Massage therapy for fibromyalgia: a systematic review and meta-analysis of randomized controlled trials. PLoS One 2014;9:e89304.

76. Yuan SL, Matsutani LA, Marques AP. Effectiveness of different styles of massage therapy in fibromyalgia: a systematic review and meta-analysis. Man Ther 2015;20:257-64.

77. Lauche R, Cramer H, Dobos G, et al. A systematic review and metaanalysis of mindfulness-based stress reduction for the fibromyalgia syndrome. J Psychosom Res 2013;75:500-10.

78. Theadom A, Cropley M, Smith HE, et al. Cochrane Musculoskeletal Group. Mind and body therapy for fibromyalgia. Cochrane Database Syst Rev 2015;13:Cd001980.

79. Bernardy K, Füber N, Klose P, et al. Efficacy of hypnosis/guided imagery in fibromyalgia syndrome--a systematic review and meta-analysis of controlled trials. BMC Musculoskelet Disord 2011:12:133

80. Mist SD, Firestone KA, Jones KD. Complementary and alternative exercise for fibromyalgia: a meta-analysis. $J$ Pain Res 2013;6:247-60.

81. Cao H, Li X, Han M, et al. Acupoint stimulation for fibromyalgia: a systematic review of randomized controlled trials. Evid Based Complement Alternat Med 2013;2013:1-15.

82. Gross A, Langevin P, Burnie SJ, et al. Cochrane Back and Neck Group. Manipulation and mobilisation for neck pain contrasted against an inactive control or another active treatment. Cochrane Database Syst Rev 2015;17.

83. Carlesso LC, Gross AR, Santaguida PL, et al. Adverse events associated with the use of cervical manipulation and mobilization for the treatment of neck pain in adults: a systematic review. Man Ther 2010;15:434-44.

84. Lin JH, Chiu TT, Hu J. Chinese manipulation for mechanical neck pain: a systematic review. Clin Rehabil 2012;26:963-73.

85. Huisman PA, Speksnijder CM, de Wijer A. The effect of thoracic spine manipulation on pain and disability in patients with non-specific neck pain: a systematic review. Disabil Rehabil 2013;35:1677-85.

86. Boyles R, Toy P, Mellon J, et al. Effectiveness of manual physical therapy in the treatment of cervical radiculopathy: a systematic review. J Man Manip Ther 2011:19:135-42.

87. Miller J, Gross A, D'Sylva J, et al. Manual therapy and exercise for neck pain: a systematic review. Man Ther 2010;15:334-54.

88. D'Sylva J, Miller J, Gross A, et al. Cervical Overview Group. Manual therapy with or without physical medicine modalities for neck pain: a systematic review. Man Ther 2010;15:415-33.

89. Trinh KV, Graham N, Gross AR, et al. Cervical Overview Group. Acupuncture for neck disorders. Cochrane Database Syst Rev 2006:CD004870.

90. Patel KC, Gross A, Graham N, et al. Massage for mechanical neck disorders. Cochrane Database Syst Rev 2012;11:CD004871.

91. White A, Foster NE, Cummings M, et al. Acupuncture treatment for chronic knee pain: a systematic review. Rheumatology 2007;46:384-90. 
92. Manheimer E, Cheng K, Linde K, et al. Cochrane Musculoskeletal Group. Acupuncture for peripheral joint osteoarthritis. Cochrane Database Syst Rev 2010;38:CD001977.

93. Cao L, Zhang XL, Gao YS, et al. Needle acupuncture for osteoarthritis of the knee. A systematic review and updated metaanalysis. Saudi Med J 2012;33:526-32.

94. Corbett MS, Rice SJ, Madurasinghe V, et al. Acupuncture and other physical treatments for the relief of pain due to osteoarthritis of the knee: network meta-analysis. Osteoarthritis Cartilage 2013;21:1290-8.

95. Turner K, Igo S. Efficacy of acupuncture in the treatment of osteoarthritis of the knee joint. Journal - Acupuncture Association of Chartered Physiotherapists 2013;2013:21-39.

96. Manyanga T, Froese M, Zarychanski R, et al. Pain management with acupuncture in osteoarthritis: a systematic review and metaanalysis. BMC Complement Altern Med 2014;14:312.

97. Hall A, Maher C, Latimer J, et al. The effectiveness of Tai Chi for chronic musculoskeletal pain conditions: a systematic review and meta-analysis. Arthritis Rheum 2009;61:717-24.

98. Kang JW, Lee MS, Posadzki P, et al. T'ai chi for the treatment of osteoarthritis: a systematic review and meta-analysis. BMJ Open 2011:1:e000035.

99. Lauche R, Langhorst J, Dobos G, et al. A systematic review and meta-analysis of Tai Chi for osteoarthritis of the knee. Complement Ther Med 2013;21:396-406.

100. Yan JH, Gu WJ, Sun J, et al. Efficacy of Tai Chi on pain, stiffness and function in patients with osteoarthritis: a meta-analysis. PLOS One 2013;8:e61672.

101. Mat S, Tan MP, Kamaruzzaman SB, et al. Physical therapies for improving balance and reducing falls risk in osteoarthritis of the knee: a systematic review. Age Ageing 2015;44:16-24.

102. Casimiro L, Barnsley L, Brosseau L, et al. Acupuncture and electroacupuncture for the treatment of rheumatoid arthritis. Cochrane Database Syst Rev 2005;38:CD003788.

103. Lee MS, Shin BC, Ernst E. Acupuncture for rheumatoid arthritis: a systematic review. Rheumatology 2008;47:1747-53.

104. Sun Z-ling, Xu X, Du S-zheng, et al. Moxibustion for treating rheumatoid arthritis: A systematic review and meta-analysis of randomized controlled trials. Eur J Integr Med 2014;6:621-30.

105. Verhagen AP, Bierma-Zeinstra SMA, Boers M, et al. Cochrane Musculoskeletal Group. Balneotherapy (or spa therapy) for rheumatoid arthritis. Cochrane Database Syst Rev 2015;25:CD000518.

106. Law D, McDonough S, Bleakley C, et al. Laser acupuncture for treating musculoskeletal pain: a systematic review with metaanalysis. J Acupunct Meridian Stud 2015;8:2-16.

107. Zhao HJ, Tan JY, Wang T, et al. Auricular therapy for chronic pain management in adults: A synthesis of evidence. Complement Ther Clin Pract 2015;21:68-78.

108. Wong Lit Wan D, Wang Y, Xue CC, et al. Local and distant acupuncture points stimulation for chronic musculoskeletal pain: A systematic review on the comparative effects. Eur J Pain 2015;19:1232-47.

109. Song $\mathrm{Y}$, $\mathrm{Lu} \mathrm{H}$, Chen $\mathrm{H}$, et al. Mindfulness intervention in the management of chronic pain and psychological comorbidity: A meta-analysis. Int J Nurs Sci 2014;1:215-23.

110. Bawa FL, Mercer SW, Atherton RJ, et al. Does mindfulness improve outcomes in patients with chronic pain? Systematic review and meta-analysis. Br J Gen Pract 2015;65:e387-e400.

111. Braun C, Hanchard NCA. Manual therapy and exercise for impingementrelated shoulder pain. Physical Therapy Reviews 2010;15:62-83.

112. Page Matthew J, Green S, Kramer S, et al. Manual therapy and exercise for adhesive capsulitis (frozen shoulder). Cochrane Database of Systematic Reviews 2014;8:CD011275.

113. Clar C, Tsertsvadze A, Court R, et al. Clinical effectiveness of manual therapy for the management of musculoskeletal and nonmusculoskeletal conditions: systematic review and update of UK evidence report. Chiropr Man Therap 2014;22:12.

114. Desjardins-Charbonneau A, Roy JS, Dionne CE, et al. The efficacy of manual therapy for rotator cuff tendinopathy: a systematic review and meta-analysis. J Orthop Sports Phys Ther 2015;45:330-50.

115. Green S, Buchbinder R, Hetrick SE. Cochrane Musculoskeletal Group. Acupuncture for shoulder pain. Cochrane Database Syst Rev 2005;7:CD005319.

116. Tough EA, White AR, Cummings TM, et al. Acupuncture and dry needling in the management of myofascial trigger point pain: a systematic review and meta-analysis of randomised controlled trials. Eur J Pain 2009;13:3-10.

117. Liu L, Huang QM, Liu QG, et al. Effectiveness of dry needling for myofascial trigger points associated with neck and shoulder pain: a systematic review and meta-analysis. Arch Phys Med Rehabil 2015;96:944-55.

118. Clark RJ, Tighe M. The effectiveness of acupuncture for plantar heel pain: a systematic review. Acupunct Med 2012;30:298-306.

119. Qin ZL, Wu Xiaoxu;, Zhai Jiani;, et al; Acupuncture for sciatica: a systematic review, 2015.

120. Bisset L, Hing W, Vicenzino B. A systematic review of the efficacy of MWM. In: Bill Vicenzino WH, Rivett D, Hall T, eds. Mobilisation with Movement: The Art and Science. Australia: Elsevier, 2011:26-63.

121. Tang $\mathrm{H}$, Fan $\mathrm{H}$, Chen $\mathrm{J}$, et al. Acupuncture for Lateral Epicondylitis: A Systematic Review. Evid Based Complement Alternat Med 2015;2015:1-13.

122. Southerst $D$, Marchand AA, Côté $P$, et al. The effectiveness of noninvasive interventions for musculoskeletal thoracic spine and chest wall pain: a systematic review by the Ontario Protocol for Traffic Injury Management (OPTIMa) collaboration. J Manipulative Physiol Ther 2015;38:521-31.

123. Piper S, Shearer HM, Côté P, et al. The effectiveness of soft-tissue therapy for the management of musculoskeletal disorders and injuries of the upper and lower extremities: A systematic review by the Ontario Protocol for Traffic Injury management (OPTIMa) collaboration. Man Ther 2016;21:18-34.

124. de Vibe M, Arlid B, Elizabeth T, et al. Mindfulness Based Stress Reduction (MBSR) for Improving Health, Quality of Life. and Social Functioning in Adults 2012.

125. Goyal M, Singh S, Sibinga EM, et al. Meditation programs for psychological stress and well-being: a systematic review and metaanalysis. JAMA Intern Med 2014;174:357-68.

126. Smith CA, Hay PPJ, MacPherson H; Cochrane Common Mental Disorders Group. Acupuncture for depression. Cochrane Database Syst Rev 2010;9:CD004046.

127. Zhang ZJ, Chen HY, Yip KC, et al. The effectiveness and safety of acupuncture therapy in depressive disorders: systematic review and meta-analysis. J Affect Disord 2010;124(1-2):9-21.

128. Wang $\mathrm{H}$, Qi H, Wang BS, et al. Is acupuncture beneficial in depression: a meta-analysis of 8 randomized controlled trials? $\mathrm{J}$ Affect Disord 2008;111(2-3):125-34.

129. Klainin-Yobas P, Oo WN, Suzanne Yew PY, et al. Effects of relaxation interventions on depression and anxiety among older adults: a systematic review. Aging Ment Health 2015;19:1043-55.

130. Cramer $\mathrm{H}$, Lauche $\mathrm{R}$, Langhorst $\mathrm{J}$, et al. Yoga for depression: a systematic review and meta-analysis. Depress Anxiety 2013;30:1068-83.

131. Maratos A, Gold C, Wang X, et al. Music therapy for depression. Cochrane Database Syst Rev 2008;25:CD004517.

132. Liu X, Clark J, Siskind D, et al. A systematic review and metaanalysis of the effects of Qigong and Tai Chi for depressive symptoms. Complement Ther Med 2015;23:516-34.

133. Joyce J, Herbison GP. Reiki for depression and anxiety. Cochrane Database Syst Rev 2015:CD006833 http://onlinelibrary.wiley.com/ doi/10.1002/14651858.CD006833.pub2/abstracthttp://onlinelibrary. wiley.com/store/10.1002/14651858.CD006833.pub2/asset/ CD006833. pdf? $v=1 \& t=i b 3 g 7 f 71 \& s=f c 7 f 57607 f 3 f 9 a b 6 e 5 f 4 c 9 e f e d b 8$ $2890 \mathrm{cbf} 11111$.

134. Chi I, Jordan-Marsh M, Guo M, et al. Tai chi and reduction of depressive symptoms for older adults: a meta-analysis of randomized trials. Geriatr Gerontol Int 2013;13:3-12.

135. Kirkwood G, Rampes H, Tuffrey V, et al. Yoga for anxiety: a systematic review of the research evidence. including commentary by Ramaratnam S. British journal of sports medicine 2005;39:884-91. discussion 91 doi:[published Online First: Epub Date.

136. Chugh-Gupta N, Baldassarre FG, Vrkljan BH. A systematic review of yoga for state anxiety: considerations for occupational therapy. Can J Occup Ther 2013;80:150-70.

137. Krisanaprakornkit T, Krisanaprakornkit W, Piyavhatkul N, et al. Meditation therapy for anxiety disorders. Cochrane Database Syst Rev 2006;1:CD004998.

138. Chen KW, Berger CC, Manheimer E, et al. Meditative therapies for reducing anxiety: a systematic review and meta-analysis of randomized controlled trials. Depress Anxiety 2012;29:545-62.

139. Pilkington K, Kirkwood G, Rampes $\mathrm{H}$, et al. Acupuncture for anxiety and anxiety disorders--a systematic literature review. Acupunct Med 2007;25(1-2):1-10.

140. Wang CW, Chan $\mathrm{CH}, \mathrm{Ho} \mathrm{RT}, \mathrm{Rt} \mathrm{H}$, et al. Managing stress and anxiety through qigong exercise in healthy adults: a systematic review and meta-analysis of randomized controlled trials. BMC Complement Altern Med 2014;14:8.

141. Wu H, Yu D, He Y, et al. Morita therapy for anxiety disorders in adults. Cochrane Database Syst Rev 2015;2:CD008619. 
142. Robinson J, Biley FC, Dolk H. Therapeutic touch for anxiety disorders. Cochrane Database Syst Rev 2007;4:CD006240.

143. Wu WW, Kwong E, Lan XY, W-w W, X-y L, et al. The Effect of a Meditative Movement Intervention on Quality of Sleep in the Elderly: A Systematic Review and Meta-Analysis. J Altern Complement Med 2015;21.

144. Neuendorf R, Wahbeh $\mathrm{H}$, Chamine I, et al. The Effects of MindBody Interventions on Sleep Quality: A Systematic Review. Evidence-Based Complementary and Alternative Medicine 2015;2015:1-17.

145. Wang F, Eun-Kyoung Lee O, Feng F, et al. The effect of meditative movement on sleep quality: A systematic review. Sleep Med Rev 2016;30:43-52.

146. Huang W, Kutner N, Bliwise DL. A systematic review of the effects of acupuncture in treating insomnia. Sleep Med Rev 2009;13:73-104.

147. Lan Y, Wu X, Tan HJ, et al. Auricular acupuncture with seed or pellet attachments for primary insomnia: a systematic review and metaanalysis. BMC Complement Altern Med 2015;15:103.

148. Du S, Dong J, Zhang H, et al. Taichi exercise for self-rated sleep quality in older people: a systematic review and meta-analysis. Int $J$ Nurs Stud 2015;52:368-79.

149. Cooper KL, Relton C. Homeopathy for insomnia: a systematic review of research evidence. Sleep Med Rev 2010;14:329-37.

150. Lam TH, Chung KF, Yeung WF, et al. Hypnotherapy for insomnia: a systematic review and meta-analysis of randomized controlled trials. Complement Ther Med 2015;23:719-32.
151. Wieland LS, Skoetz N, Pilkington K, et al. Yoga treatment for chronic non-specific low back pain. Cochrane Database Syst Rev 2017;1:CD010671.

152. Hilton L, Hempel S, Ewing BA, et al. Mindfulness Meditation for Chronic Pain: Systematic Review and Meta-analysis. Ann Behav Med 2017;51:199-213.

153. Anheyer D, Haller H, Barth J, et al. Mindfulness-Based Stress Reduction for Treating Low Back Pain: A Systematic Review and Meta-analysis. Ann Intern Med 2017;166:799-807.

154. Shim JW, Jung JY, Kim SS. Effects of Electroacupuncture for Knee Osteoarthritis: A Systematic Review and Meta-Analysis. Evid Based Complement Alternat Med 2016;2016:1-18.

155. Lin X, Huang K, Zhu G, et al. The Effects of Acupuncture on Chronic Knee Pain Due to Osteoarthritis: A Meta-Analysis. J Bone Joint Surg Am 2016;98:1578-85.

156. Shea BJ, Reeves BC, Wells G, et al. AMSTAR 2: a critical appraisal tool for systematic reviews that include randomised or nonrandomised studies of healthcare interventions, or both. BMJ 2017;358:j4008.

157. Linde K. Can you trust systematic reviews of complementary and alternative therapies? Eur J Integr Med 2009;1:117-23.

158. Verhoef MJ, Lewith G, Ritenbaugh C, et al. Complementary and alternative medicine whole systems research: beyond identification of inadequacies of the RCT. Complement Ther Med 2005;13:206-12.

159. Carter B. Methodological issues and complementary therapies: researching intangibles? Complement Ther Nurs Midwifery 2003;9:133-9. 